\title{
Human evacuation affected by smoke movement in mine fires
}

\author{
Peng Chen ${ }^{1} \cdot$ Shilong Guo ${ }^{1} \cdot$ Yong Wang ${ }^{1}$
}

Received: 28 February 2015/Revised: 16 March 2015/ Accepted: 27 October 2015/Published online: 29 January 2016

(C) The Author(s) 2016. This article is published with open access at Springerlink.com

\begin{abstract}
The objective of this work is to investigate the influence of smoke movement during mine fires on miner evacuation behaviors. A three-dimensional computational fluid dynamics method was conducted to reconstruct the laneway conveyor belt fire scenes under two ventilating conditions. The parameters, including temperature-time histories, soot density, carbon monoxide and heat release rate, were simulated to characterize the mine fires at various ventilating speeds. A miner evacuation model affected by fire smoke movement was advanced to describe the miner evacuation behaviors, which can be divided into three stages. Based on the evacuation model coupled with the mine fire smoke movement, the available safety evacuation time for miners involved in coal mine fire located in different sites was estimated. Two evacuation patterns were advanced according to the ventilating speeds combined with the model of miner evacuation behaviors. The results show that the miners located between the inlet-air end and the air door in lane 1 should be evacuated to the inlet-air end and other miners involved in coal mine fire could choose the air door as the escaping destination, when the ventilation speed is greater than $3 \mathrm{~m} / \mathrm{s}$. Accordingly, the research can be used as references for the mine safety administration authorities to design the safety evacuation.
\end{abstract}

Keywords Mine fires $\cdot$ Smoke movement $\cdot$ Evacuation behaviors $\cdot$ Evacuation patterns

\section{Introduction}

Miners involved in disaster sites, expect to evacuate to a safe place as soon as possible, when calamities happen in coal mines. In fact, the miners cannot quickly identify the danger zones area due to the complexities of coal mine environment. The miners usually begin to evacuate when they are informed by the mine safety inspection system, or apperceive the fire signals produced by the fire smoke. The casualty happens if the miners could not choose the optimizing paths to withdraw from the danger places, for the smoke movement encumbers the evacuation of coal

Peng Chen

chenpeng@cumtb.edu.cn

1 College of Resources and Safety Engineering, China University of Mining and Technology (Beijing), Beijing 100083, China miners. Therefore it is a key task for the mine safety administration authorities to improve the controlling ability of disasters and cognition capability of accident development. Thus, the casualties of coal mine can be efficiently reduced or prevented. The injuries and deaths involved in the mine fires relate closely to the human evacuation behaviors, which are impacted by smoke movement. To fully reinsure the miner safety, the human evacuation strategy in mine fires should be taken into account.

To date, abundant and miscellaneous documents about coal mine fires are generated (Bell et al. 2001; Huang et al. 2001; Kunsch 2002; Stracher and Taylor 2004; Kuenzer et al. 2007; Grayson et al. 2009). Among the coal mine fires, the conveyor belts are the primary dangerous combustive materials, which can be ignited by the frictional heating. Perzak et al. (1995) calculated the heat release rate of the conveyor belts based on the $\mathrm{CO}$ and $\mathrm{CO}_{2}$ concentrations measured at the exit of the tunnel. Cheng et al. (2002) conducted a series of experiments on the convey 
belt fires in the mines and gained much useful data including ignition energy, heat release rates, and smoke toxicity. Charles and Perera (2012) simulated the typical fires that developed along conveyor belt transport systems within underground coal mines by large-scale experiments. Lowndes et al. (2007) conducted an experimental and computational study to characterize the initiation and spreading of the fires along the upper and lower surfaces of a conveyor belt mounted within a ventilated full-scale experimental fire test gallery. Yuan et al. (2014) gained a series of experiment data at the exit of the large-scale tunnel, including maximum heat release rate, downstream maximum smoke temperature, and maximum $\mathrm{CO}$ concentration which are reproduced by simulation. Human evacuation behaviors could be influenced by the fire smoke movement (Huang et al. 2013). Huo et al. (2014) discussed the characteristics of human evacuation behaviors and analyzed the evacuation time and specific flow in underground evacuation scenario. Ji et al. (2010) developed a visual model of evacuation to simulate the evacuation process of mines under the special underground environments. Wang et al. (2014) established a framework for human error risk analysis of coal mine emergency evacuation and proposed a method based on expert judgment to evaluate the reliability of human safety barrier. However, few researchers are proceeding with the influence of smoke movements on underground coal mine evacuation behaviors. The aim of this paper is to discuss the smoke movement in a mine lane, the miner behaviors under the influence of fire smoke, and the choice of the evacuation paths. Thus effective safety evacuation models can be advanced.

\section{Safety evacuation guidelines for miners involved in coal mine fires}

The evacuation behaviors involved in mine fires commonly can usually be divided into four stages: fire receipt, preparation, evacuation action and reaching the safe sites. Therein, there are three key moments for evacuation as follows: finding the fire point, issuing the alarm, and miners in danger. Similarity to the civil building fire evacuation (Fruin 1971), a time judgment model on miner safety evacuation can be advanced. Its model scheme is shown in Fig. 1. In order to ensure safety evacuation of miners involved in coal mine fires, the requested safety evacuation time (RSET) must be less than available safety evacuation time (ASET).

\subsection{Requested safety evacuation time}

RSET goes through ignition to the moment when the miners evacuate to the safe sites. It includes fire detecting time $\left(T_{\text {alarm }}\right)$, preparation action time $\left(T_{\text {pre }}\right)$ and human

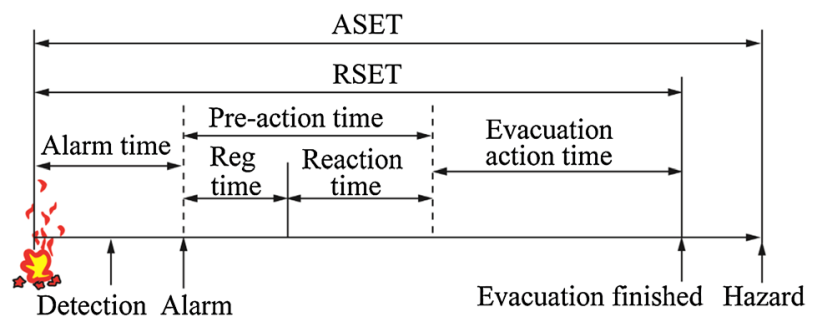

Fig. 1 Time judgment of miner safety evacuation (Fruin 1971)

evacuation time. The preparation time consists of reorganization time $\left(T_{\text {reg }}\right)$ and reaction time $\left(T_{\text {resp }}\right)$.

The coal mine fire detecting time relies on both mine fire types and characteristic of safety inspect system. The miner evacuation movement time depends on personnel density, evacuation speed and breadth of safety exit. However, the preparation action time could hardly be estimated due to the miners psychology, ages and familiar degree to coal mine lanes.

\subsection{Available safety evacuation time}

Based on the fire risk engineering evaluation theory (Fruin 1971), if RSET is less than ASET, the miners involved in mine fire could be safely evacuated. It can be expressed as ASET > RSET

In coal mine fires, a reasonable path should be selected to avoid the heavy casualties on account of this requirement, coupled with the characteristics of the mine fire and miner behaviors.

\subsection{Numerical methods}

Fire dynamic simulator (FDS) is the useful software to simulate the smoke distribution and the temperature field in an enclosure fire based on a three-dimensional and largeeddy model (Lin 2014; Yuan et al. 2014). Its simulation results are good agreement with experimental data in numerous validation studies. The schematic drawing of the simulation model is shown in Fig. 2. The lane is a horizontal rectangular duct with a cross section $4.5 \mathrm{~m}$ in height by $2.5 \mathrm{~m}$ in width. Laneway 1 is an air intake tunnel by $72 \mathrm{~m}$ long, and an air door locates on its right side. The door is $1 \mathrm{~m}$ in width by $2 \mathrm{~m}$ in height. Laneway 2 is an air return tunnel by $30 \mathrm{~m}$ long. Two conditions are assumed for the simulation: opening the air door or not. A conveyor belt, $5 \mathrm{~m}$ in length by $1 \mathrm{~m}$ in width, is located $5 \mathrm{~m}$ away from the air intake entry.

The computation domain is divided into minor three dimensional girds $0.5 \mathrm{~m} \times 0.5 \mathrm{~m} \times 0.5 \mathrm{~m}$. An ignition source, $1 \mathrm{~m}$ long by $0.5 \mathrm{~m}$ wide in size, is placed at the upstream end of the conveyor belt, whose heat release rate 


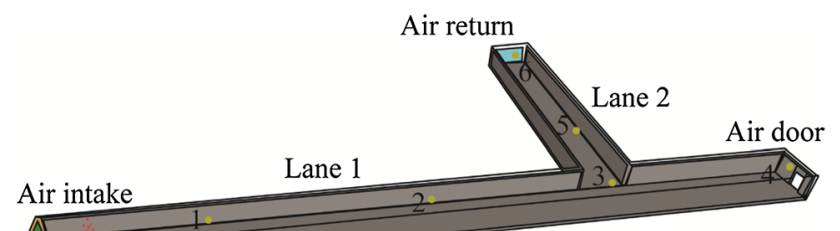

Fig. 2 Typical computation model of lane fire

Table 1 Material properties

\begin{tabular}{ll}
\hline Property & Value \\
\hline Density $\left(\mathrm{kg} / \mathrm{m}^{3}\right)$ & 1300 \\
Specific heat $(\mathrm{kJ} / \mathrm{kg} \mathrm{K})$ & 1.3 \\
Conductivity $(\mathrm{W} / \mathrm{m} \mathrm{K})$ & 0.19 \\
Heat of combustion $(\mathrm{kJ} / \mathrm{kg})$ & 28,500 \\
Heat of gasification $(\mathrm{kJ} / \mathrm{kg})$ & 1500 \\
Reference temperature $\left({ }^{\circ} \mathrm{C}\right)$ & 370 \\
\hline
\end{tabular}

is $1000 \mathrm{~kW}$ per unit area. The conveyor belt is a kind of combustive polymer material, polyvinyl chloride (PVC), and its properties are listed in Table 1 . To investigate the influence of air flow on fire smoke development, the ventilation speeds are set as $0.3,1.5,3.0$, and $4.0 \mathrm{~m} / \mathrm{s}$. The temperature, smoke density and visibility are recorded at $z=1.5 \mathrm{~m}$ in the laneway.

\section{Results and discussion}

\subsection{Coal mine fire smoke movement}

The simulated temperature-time histories of smoke development at the different measured points are given in Fig. 3. The temperature decreases with the increasing distance away from the fire source. Compared the case of the air door opened with that of the air door closed, the temperature distribution is distinctly influenced by the air door switching status. The temperature increasing rates for the air door closed are greater than that for the air door opened. While air door is opened, the conveyer belt gets into general conflagration at $t=320 \mathrm{~s}$. It leads to the occurrences of temperature crests, and the maximal temperature is about $353{ }^{\circ} \mathrm{C}$. When conveyer belt burns out, the temperatures decrease dramatically to the ambient temperature. While the air door is closed, a smooth combustion appears at the time of $200 \mathrm{~s}$. Its maximum smoke temperature is $128{ }^{\circ} \mathrm{C}$.

The soot density is shown in Fig. 4. While the air door is opened, the soot densities of all measuring points have steep peaks. The maximal value at measuring point 1 is $3.6 \times 10^{-3} \mathrm{~kg} / \mathrm{m}^{3}$, and the maximal one is $1.5 \times 10^{-3} \mathrm{~kg} /$ $\mathrm{m}^{3}$ when the air door is closed. The soot density at measuring point 4 in both cases is higher than those measured
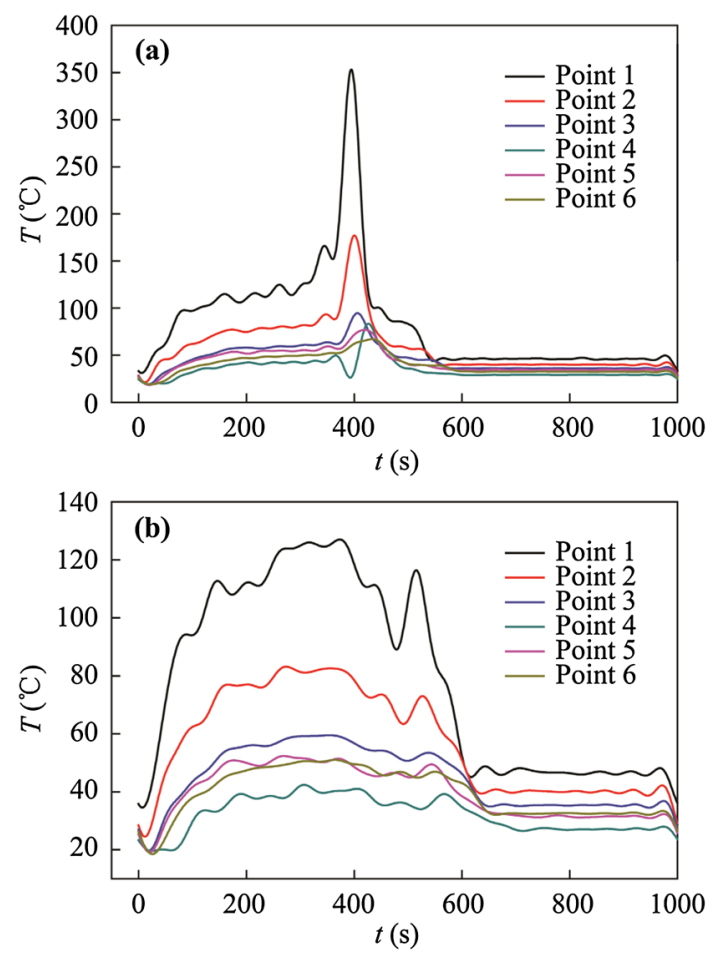

Fig. 3 Smoke temperature distributions in computed lane. a Air door opened; $\mathbf{b}$ air door closed
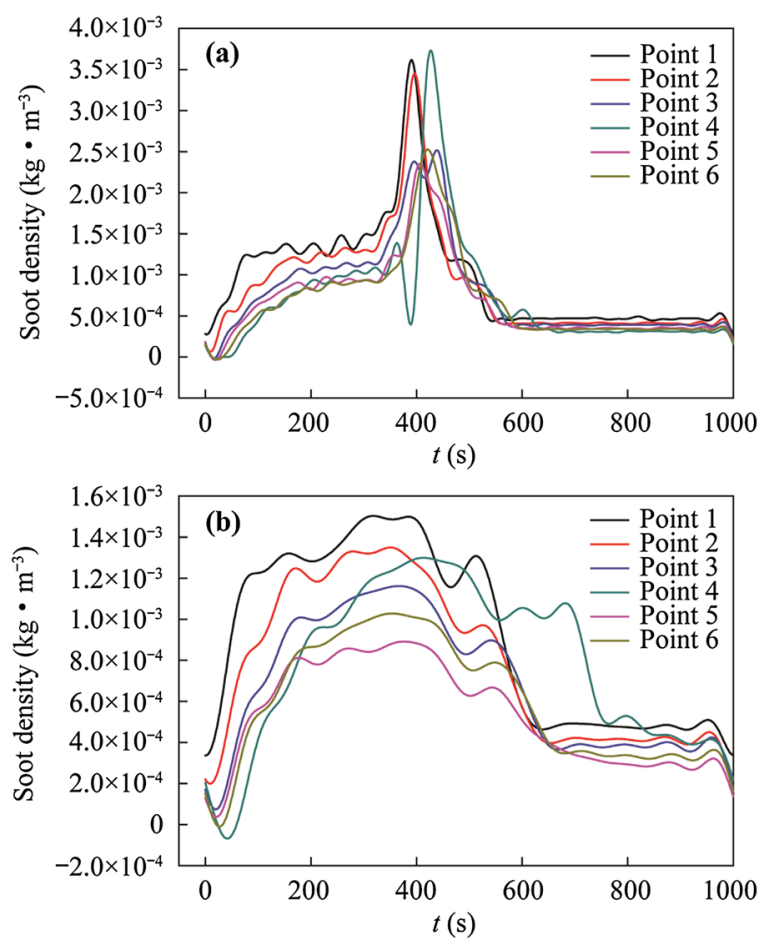

Fig. 4 Soot density distribution in computed lane. a Air door opened; b air door closed

at other points except for the measured point 1 . The soot density curve at point 4 presents two peaks and the second one is larger, for this measured point is near to the air door. 

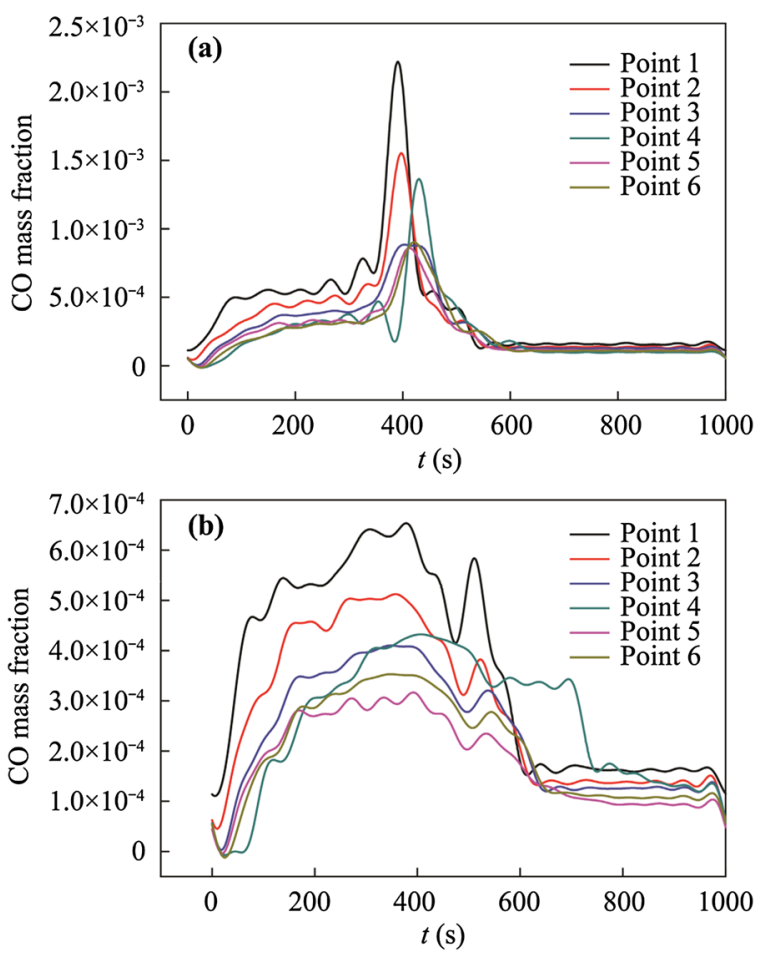

Fig. $5 \mathrm{CO}$ mass fraction distributions in computed lane. a Air door opened; $\mathbf{b}$ air door closed

The results show that the smoke tends to assemble at the end of lane 1.

Carbon monoxide (CO) is a poisonous gas in mine fires, and its mass fraction is often used as a index to judge whether the fire threat the miner lives. The $\mathrm{CO}$ mass fraction is shown in Fig. 5. The maximum value of $\mathrm{CO}$ mass fraction is $2.24 \times 10^{-3}$, which is smaller than the standard values. It demonstrates that $\mathrm{CO}$ produced by the conveyer belt fire is not fatal to the living beings.

Heat release rate is one of the most important parameters used to evaluate the overall hazard of a fire. The total heat release rates are shown in Fig. 6. The maximal heat release rate changes from 7.5 to $2 \mathrm{MW}$ when the air door switches from opening to closing.

\subsection{Miner evacuation model affected by fire smoke movement}

For the fire smoke is lightproof, miners usually feel scared and nervous in a closed roadway filled with the smoke. This emotion prevents them from acting consciously. In addition, the smoke contains large amount of noxious gasses, such as $\mathrm{CO}, \mathrm{HCN}$ etc. These noxious gasses will hurt miners' eyes and central nervous systems, decline their visual acuity and thinking ability, and make them unconscious, which potentially increase the RSET. Danger limit states in coal mine fire are the cases that fire environments could cause the

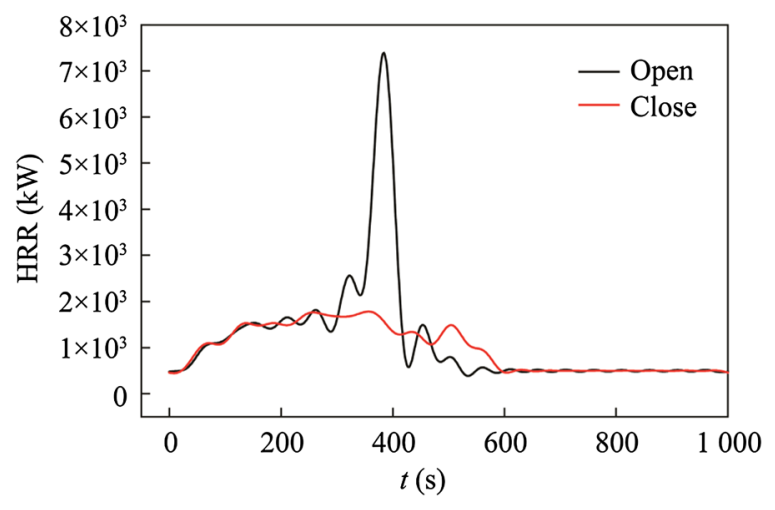

Fig. 6 Heat release rate distribution in computed lane

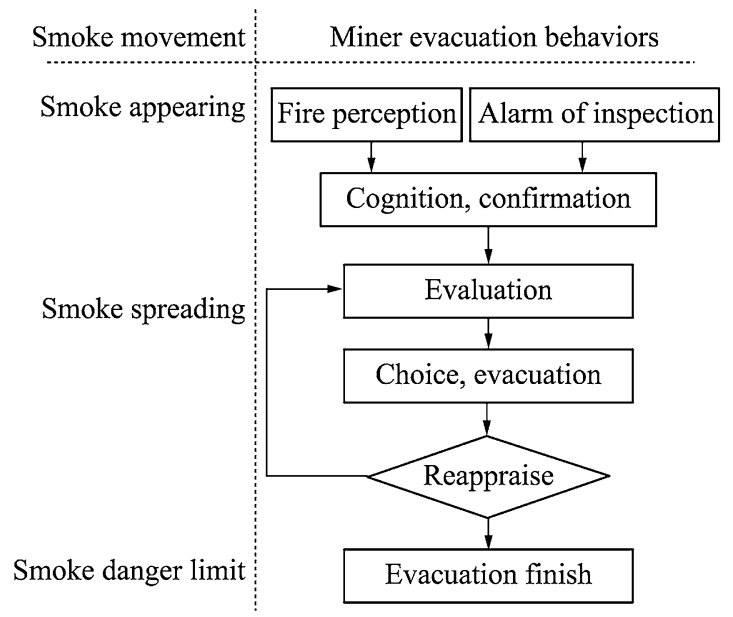

Fig. 7 Relationship of miner evacuation behaviors process with smoke movement

miners severity damage. So the miners should keep away from the dangerous lanes caused by smoke movement, or evacuate to a safe place before the dangerous states start.

The model of miner evacuation behaviors affected by the smoke movement in the mine fires is given in Fig. 7. Based on the mine fire smoke development, the evacuation behaviors in coal mine fires can be divided into three stages. The smoke generates in the early stage of most fires, so the appearance of smoke is regarded as the symbol of the first stage. The alarm in this stage can help the miners to evacuate smoothly. The smoke detecting system reminds the miners, who are in dangerous, when the smoke density reaches preset value. After a short response time, most miners begin to evacuate. The perception of the fires can be informed by other miners, or stimulated by fire products such as the flames, smokes and high temperatures. A quick fire perception can help the miners evacuate successfully. In the second stage, the conveyor belt starts to burn fully and the smoke could extend to fill with the full lane. It is critical for the miner to evacuate safely. Through cognition 


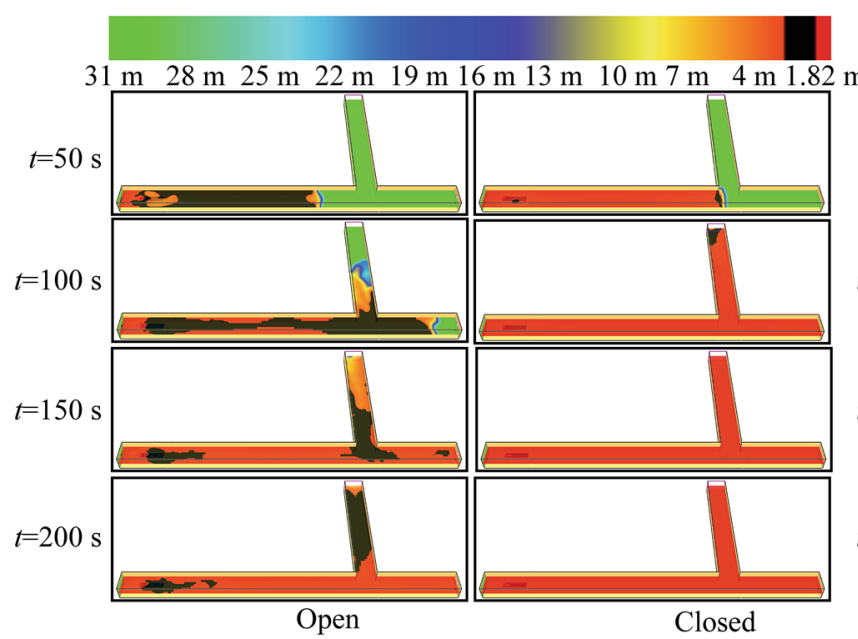

(a) Ventilating speed is $0.3 \mathrm{~m} / \mathrm{s}$

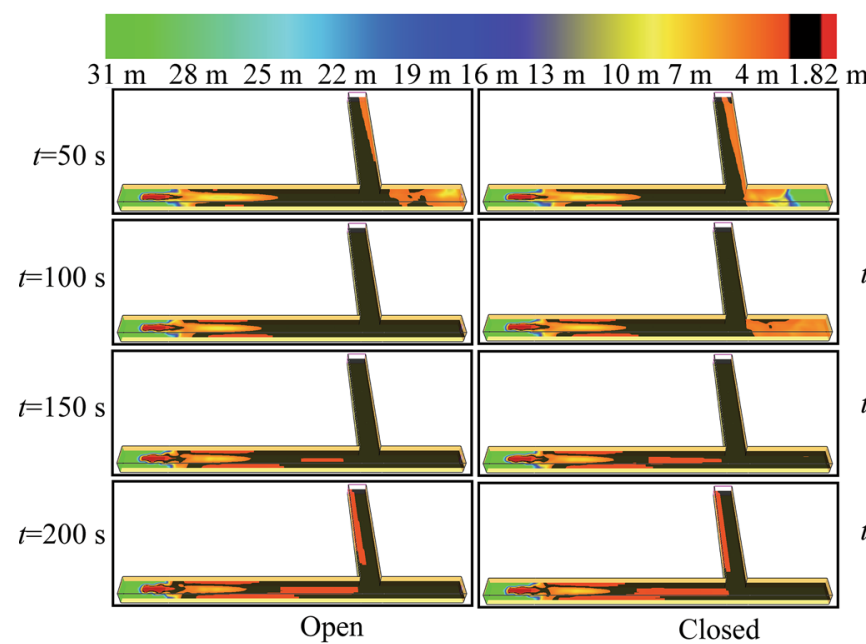

(c) Ventilating speed is $3.0 \mathrm{~m} / \mathrm{s}$

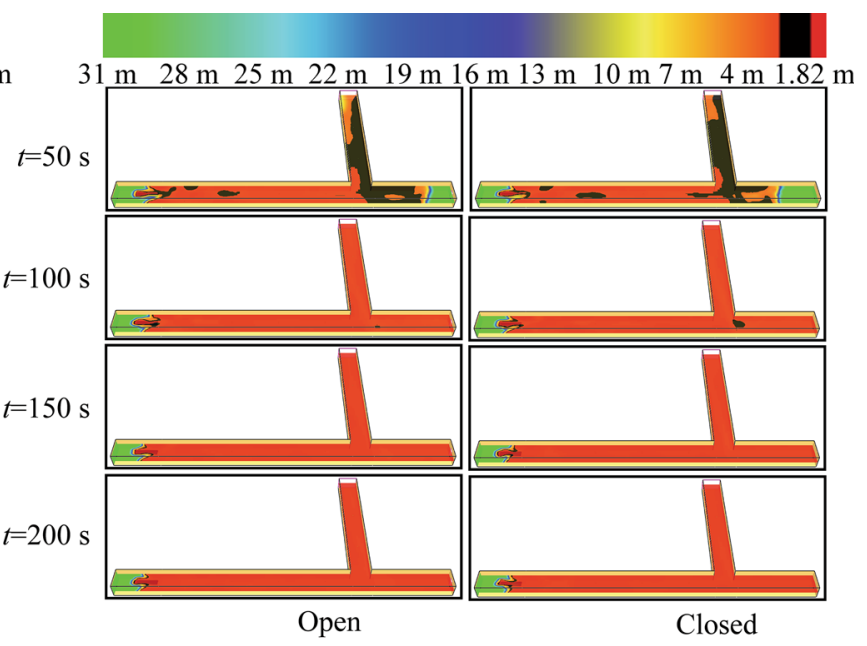

(b) Ventilating speed is $1.3 \mathrm{~m} / \mathrm{s}$

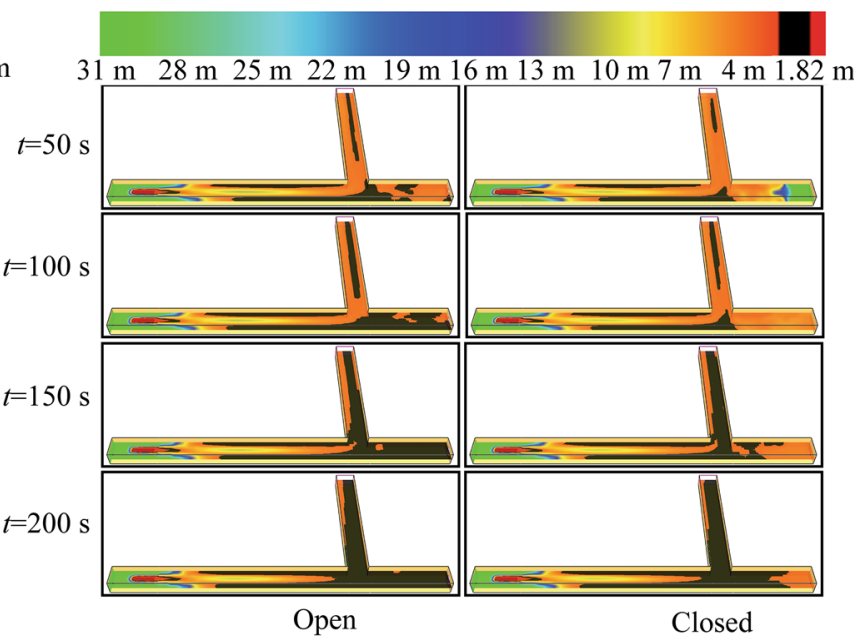

(d) Ventilating speed is $4.0 \mathrm{~m} / \mathrm{s}$

Fig. 8 Visibility distribution with time in computed lane

and confirmation, the miners can evaluate the fire risk by estimating the surrounding environment. The miners rapidly response and adapt to the new conditions. They begin to deal with the fires, and their behaviors include as follows: finding the igniting source, controlling the fire spreading, informing and assisting other miners, calling the fire brigade for help, directly fleeing, and incapable acting due to panic. In the third stage, the fire smoke almost fills with the lane. A large amount of high temperature smoke can lead to death, and the evacuation finished.

\subsection{Miner evacuation behaviors affected by fire smoke movement}

\subsubsection{Available safety evacuation time}

The limitation of the dangerous fire status can be figured out by the smoke temperature, the noxious gas concentration and the smoke visibility. The dangerous smoke temperature to hurt the epidermis can be evaluated by the heat radiation and the skin exposure time under a high temperature. While the skin exposure time reaches to $60 \mathrm{~s}$ and its environmental temperature is $71{ }^{\circ} \mathrm{C}$, the degree of the skin injury could come to two level. When the environmental temperature is $82^{\circ} \mathrm{C}$ and the exposure time is $30 \mathrm{~s}$, a two level injury can appear as well. The harmful smoke concentration could be determined by the limiting concentration of some poisonous gases in the fire smoke, when the smoke descends to a height where human breathe. Here the height is the normal distance from the ground, and denoted by $z$. The miners are incapable of finding effective escaping routes when the fire smoke drops to $1.82 \mathrm{~m}$ in height. ASET can be calculated according to the limitation parameters as follows:

(1) The smoke temperature rises to $65{ }^{\circ} \mathrm{C}$ at $z=1.5 \mathrm{~m}$.

(2) The smoke visibility falls to $1.82 \mathrm{~m}$ at $z=1.5 \mathrm{~m}$. 


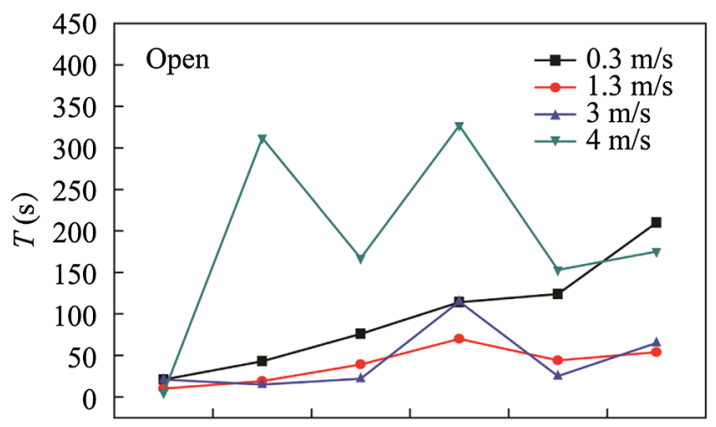

Point 1 Point 2 Point 3 Point 4 Point 5 Point 6

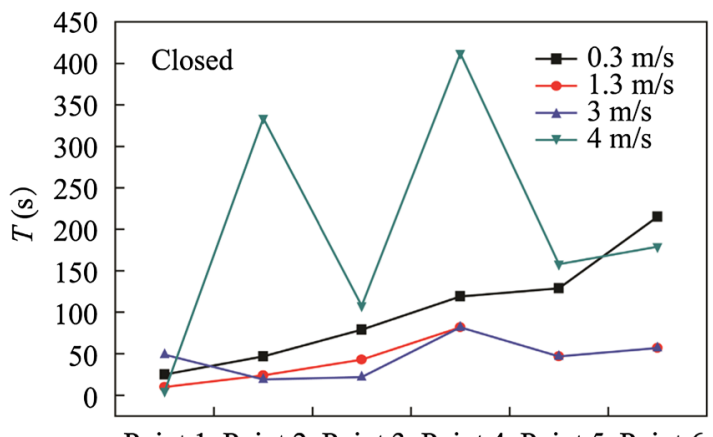

Point 1 Point 2 Point 3 Point 4 Point 5 Point 6

Fig. 9 Available safety evacuation time (ASET) at different points

If the fire products accumulate to the critical values, the miners located in this site are thought to be in danger. According to the simulated results, the dangerous limitation of smoke visibility always precedes that of smoke temperature. Therefore, the smoke visibility is used to recognize the dangerous moments. The distribution of the smoke visibility at $z=1.5 \mathrm{~m}$ is shown in Fig. 8 .

In the light of the limitation parameters, the required time for escaping from different points to air vents can be calculated as shown in Fig. 9. And this time could be regarded as ASET.

\subsubsection{Evacuation behaviors affected by the fire smoke movement}

The optimum evacuation routines could be determined by ASET. There are two evacuation patterns on the basis of both the ventilating speeds and the miner evacuation behaviors' model.

(1) When the ventilation speed is less than $3 \mathrm{~m} / \mathrm{s}$, the miners in lane 1 should evacuate to the upstream side of the fire scene, and the miners in lane 2 could select either the air intake end or the air door as the evacuation destination.

(2) When the ventilation speed is greater than $3 \mathrm{~m} / \mathrm{s}$, the miners located between the measuring point 4 and the inlet-air end in lane 1 should be evacuated to the inlet-air end, and other miners involved in fires could choose the air door as the escaping destination.

In general, the evacuation design should fully consider both the models of the miner behaviors involved in fires and the characteristics of the fire smoke movement. In addition, the psychology and behavior patterns, such as phototactic behavior, conformity behavior, and homing behavior, should be fully considered during the evacuation of coal mine fires. Thus the probability of the successful evacuation could be achieved.

\section{Conclusions}

Miner evacuation affected by mine fire smoke movement has been investigated, and the following conclusions are obtained:

(1) The parameters, including the temperature distribution, soot density, $\mathrm{CO}$ and heat release rate, are simulated to characterize the mine fires at different ventilating speeds. The results demonstrate that the conveyor belt burns more vigorously under the case of the air door opened than that of the air door closed. A miner evacuation model affected by fire smoke movement is advanced, and it is concluded that the miner evacuation behaviors can be divided into three stages.

(2) Based on the dangerous limitation parameters of the mine fire smoke, the evacuating time at the different points in the lanes is calculated, and the optimal evacuation routines could be selected. The results show that ASET changes with the ventilation speeds. The descending order of the ASET values under various ventilation speeds can be sorted as follows: $4,0.3$, and $3 \mathrm{~m} / \mathrm{s}$.

(3) Two evacuation patterns affected by the ventilation speeds are advanced. The miners located between the air door and the inlet-air end in lane 1 should be evacuated to the inlet-air end, and other miners involved in coal mine fire could select the air door as the evacuating destination, when the ventilation speed is greater than $3 \mathrm{~m} / \mathrm{s}$.

Acknowledgments This work is supported by National Natural Science Foundation of China (51274205), the Doctoral Program Foundation of Ministry of Education the New Teacher Project (20070290022) and the Open Project of China University of Mining and Technology Resources and Mine Safety State Key Laboratory (SKLCRSM10KFB13). 
Open Access This article is distributed under the terms of the Creative Commons Attribution 4.0 International License (http://crea tivecommons.org/licenses/by/4.0/), which permits unrestricted use, distribution, and reproduction in any medium, provided you give appropriate credit to the original author(s) and the source, provide a link to the Creative Commons license, and indicate if changes were made.

\section{References}

Bell FG, Bullock SET, Halbich TFJ, Lindsay P (2001) Environmental impacts associated with an abandoned mine in the Witbank coalfire, South Africa. Int J Coal Geol 45(2-3):195-216

Charles DL, Perera Inoka Eranda (2012) Evaluation of criteria for the detection of fires in underground conveyor belt haulageways. Fire Saf J 51:110-119

Cheng YP, Ji JW, Li ZH (2002) Experiment study on burning capability of conveyer belts of mines in fire process. J Liaoning Tech Univ 21(1):90-92

Fruin JJ (1971) Designing for pedestrians: a level-of-service concept. Highw Res Board 355:1-15

Grayson RL, Kinilakodi H, Kecojevic V (2009) Pilot sample risk analysis for underground coal mine fires and explosions using MSHA citation data. Saf Sci 47:1371-1378

Huang JJ, Bruining J, Wolf K-HAA (2001) Modeling of gas flow and temperature fields in underground coal fires. Fire Saf $\mathrm{J}$ 36(5):477-489

Huang LL, Zhu GQ, Zhang GW, Yin F (2013) Research the occupants safe egress of underground pedestrian street based on the analysis of fire smoke movement. Procedia Eng 52:158-164

Huo FZ, Song WG, Liu XD, Jiang ZG, Liew KM (2014) Investigation of human behavior in emergent evacuation from an underground retail store. Procedia Eng 71:350-356
Ji JW, Zhang JY, Chen JL, Wu S (2010) Computer simulation of evacuation in underground coal mines. Min Sci Technol 20(5):677-681

Kuenzer C, Zhang J, Li J, Voigt S, Mehl H, Wagner W (2007) Detection of unknown coal fires: synergy of coal fire risk area delineation and improved thermal anomaly extraction. Int $\mathbf{J}$ Remote Sens 28(20):4561-4585

Kunsch JP (2002) Simple model for control of fire gases in a ventilated tunnel. Fire Saf J 37(1):67-81

Lin P, Lo SM, Li T (2014) Numerical study on the impact of gradient on semi-transverse smoke control system in tunnel. Tunn Undergr Sp Technol 44:68-79

Lowndes IS, Silvester SA, Giddings D, Pickering S, Hassan A, Lester E (2007) The computational modelling of flame spread along a conveyor belt. Fire Saf J 42(1):51-67

Perzak FJ, Litton CD, Mura KE, Lazzara CP (1995) Hazards of conveyor belt fires. Report of Investigation 9570, U.S. Bureau of Mines

Stracher GB, Taylor TP (2004) Coal fires burning out of control around the world: thermodynamic recipe for environmental catastrophe. Int J Coal Geol 59(1-2):7-17

Wang LJ, Wang YL, Cao QY, Li XD, Li JQ, Wu XW (2014) A framework for human error risk analysis of coal mine emergency evacuation in China. J Loss Prev Process Ind 30:113-123

Yuan LM, Mainiero RJ, Rowland JH, Thomas RA, Smith AC (2014) Numerical and experimental study on flame spread over conveyor belts in a large-scale tunnel. J Loss Prev Process Ind 30(21):253-257 